\section{Divided by a common language}

SIR - Koreaki Ito's suggestion (Nature 382, 666; 1996) that British spellings be abandoned in favour of US spellings to assist in electronic searching of databases has led to an interesting correspondence. A solution has already been implemented, at least with some database software. Stephen Smith referred to this solution in his letter (Nature 383, 384; 1996): intelligent programming.

The UNESCO CDS/ISIS software, which is widely used in libraries and museums across the world, allows us to define such a look-up table, so that whether (behaviour or behavior) or (Nicrophorus or Necrophorus) (A. T. Schafer, Nature 383, $384 ; 1996)$ is keyed in does not matter. The National Information Services Corporation (NISC) ROMWRIGHT software now provides automatic searching for plural/ singular forms (fish/fishes), international and other spelling variants (harbour/ harbor), and different constructions for compound words (groundwater/ground water/ground-water). I am sure that there is other software that provides the same facilities. What is now needed is pressure on database hosts and other vendors to provide the same facilities in their software. This seems a much more acceptable solution than trying to impose English or American spellings (or Australian or...).

David S. Moulder

National Marine Biological Library,

Plymouth Marine Laboratory/

Marine Biological Association,

Plymouth PL1 2PB, UK

e-mail: d.moulder@pml.ac.uk

SIR - J. T. C. Sellick (Nature 383, 569; 1996) has my sympathy. My family name is Ambrogi Lorenzini (without hyphen); my given name is Carlo. But Current Contents persists, in spite of my protests, in listing me as C. A. Lorenzini, which is both annoying and damaging. The reason is apparently that their computer software, following American usage, treats as a middle name any name coming after the given name when followed by another name.

\section{Carlo Ambrogi Lorenzini}

Dipartimento di Scienze Fisiologiche,

Universita degli Studi di Firenze,

1-50134 Firenze, Italy

SIR - I was interested in the letter from L. M. Corrochano about authors with two surnames and their treatment by bibliographic databases. The correct citation of an author's name is vital for it's subsequent retrieval, and databases usually have measures in place to ensure that names of authors are cited correctly.

That is certainly the case with $\mathrm{CAB}$ ABSTRACTS and CAB HEALTH, the databases produced by CAB INTERNATIONAL Information Institute. These databases cover the world literature in agriculture and some aspects of human health, and so we have rules, based on international standards, covering the citation of authors' names for many nationalities. To give a few examples, Chinese, Indian and Hungarian names present their own problems. (See also Zainab Awang Ngah, in "Malay names: current practices in ascertaining the form of headings and sources for reference", Asian Libraries 5 (1), 19-33; 1996.) Transliteration is necessary for names from Cyrillic and Greek scripts, and we include author variants, wherever possible, to help the searcher to retrieve all relevant papers.

For Spanish names the rule is to cite both surnames when given, even when the second one is abbreviated to an initial (Juan Carlos Palacios C., for example, is cited as Palacios C., J. C.). However, for other nationalities where we are sure that they are surnames the rule is to cite only the last of the names, thus Sellick, J. T. C. Where they are hyphenated, both names are cited, thus Clark-Sellick, J. T.

Corrochano suggests that the option of hyphenating surnames keeps journal editors and database curators happy. It should also keep the authors themselves and database users happy, if the names are cited properly.

Mike Hails (Hails, M. R.)

CAB INTERNATIONAL,

Wallingford, Oxon OX10 8DE, UK

\section{Pump priming works in Singapore}

SIR - Terence Kealey (Nature 383, 474; 1996) claims that because of the establishment in Singapore of the National Science and Technology Board (NSTB) and the National Technology Plan in 1991, the rate of growth in the total research and development (R\&D) budget fell after 1992. He claims that this is consistent with the laws of scientific research that he published in his book The Economic Laws of Scientific Research. measured most accurately by comparing the period just before and after its formation.

NSTB was formed in 1991 to promote economically relevant $R \& D$ in Singapore with the aim of enhancing our economic competitiveness. Before the formation of NSTB, from 1987 to 1990, GERD (gross expenditure on $R \& D$ ) was growing at a compound annual growth rate (CAGR) of $15 \%$ (see table). However, since the forma-
The effectiveness of NSTB can be tion of NSTB in 1991, GERD growth from 1990 to 1995 had a CAGR of $19 \%$. This is more than double the GERD registered five years ago. Therefore, the rate of GERD growth since the formation of NSTB has been more significant in the past five years, compared to the few years before its formation.

Second, private sector GERD grew at a CAGR of $11 \%$ from 1987 to 1990 . Howev-

\begin{tabular}{llc}
\hline \multicolumn{3}{c}{ GROWTH OF ECONOMICALLY RELEVANT R\&D } \\
$\begin{array}{l}\text { Gross expenditure on } \\
\quad 1987-90\end{array}$ & $1990-95$ \\
$\quad$ R\&D (GERD) & $15 \%$ & $19 \%$ \\
$\begin{array}{l}\text { Private sector expenditure } \\
\text { on R\&D }\end{array}$ & $11.1 \%$ & $23.3 \%$ \\
\hline
\end{tabular}

er, between the formation of NSTB in 1991 and 1995, private sector GERD has been growing at a CAGR of $23 \%$ annually. So the rate of growth of private sector GERD after the formation of NSTB is more than double that in 1987-90. Furthermore, private sector GERD growth since 1990 (at $23 \%$ CAGR) even exceeds that for overall GERD, which grew at a CAGR of $19 \%$ annually. So government funding had not only not displaced private sector expenditure on $R \& D$, but it had also stimulated greater $\mathrm{R} \& \mathrm{D}$ growth in the private sector. In fact the share of private sector GERD increased from $54 \%$ in 1990 to $64.5 \%$ in 1995.

\section{Lee Kheng Cheok}

Planning and Policy Division,

National Science and Technology Board,

10 Science Park Road, The Alpha,

Singapore Science Park II,

Singapore 117684

\section{No relation}

SIR - Philip Anderson's otherwise excellent obituary of Sir Nevil Mott (Nature 383, 121 ; 1996) quite erroneously makes me Mott's nephew by marriage. There is no such relationship.

Charles Frank

Orchard Cottage, Grove Road,

Coombe Dingle, Bristol BS9 2RL, UK

\section{Nothing new}

SIR - Doo Jung Jin (Nature 383, 662; 1996) would. rename the kilogram "einstein" on the grounds that it is the only SI basic unit that is a multiple of another unit. Is (s)he aware that the einstein is a photochemical unit corresponding to Avogadro's number of photons?

Gerald E. Smyth

Nippon Shinyaku Co. Ltd,

Nishiohji-Hachijo,

Minami-ku,

Kyoto 601, Japan 